\title{
Ultrasound in rural India: A failure of the best intentions
}

\author{
GAJANAN PHUTKE, TIMOTHY S LAUX, PRIYANK JAIN, YOGESH JAIN
}

\begin{abstract}
The Pre-Conception and Pre-Natal Diagnostic Techniques Act was written to prevent societally unacceptable harms including intentional sex selection. The pragmatism required to enforce this law has profound effects on the ability of rural Indians to access diagnostic ultrasonography. In so doing, it may have inadvertently placed a heavier burden on the poorest and worsened health inequity in India, creating serious ethical and justice concerns.
\end{abstract}

It is time to re-examine and update the law such that diagnostic ultrasonography is widely available in even the most peripheral primary health and community health centres. Shorter, more accessible ultrasonography training courses should be offered; collaboration between radiologists and rural practitioners and facilities should be encouraged. Finally, modern ultrasound machines can carefully record all images via a "silent observer" modality. With some modifications to previously used silent observer modalities, this technology allows both greater access and better policing of potential misuse of ultrasound technology.

\section{Laws concerning sex selection}

In 1994, India passed the Pre-Natal Diagnostic Techniques (Regulation and Prevention of Misuse) Act (PNDT). This law was a further extension of regional laws previously passed banning the use of amniocentesis or chorionic villus biopsy for sex selection, in response to the skewed male-female sex ratios seen in many parts of India $(1,2)$ and later research which implicated the selective abortion of female foetuses as the most likely driver of "missing" annual female births (3). While this law did not ban the abortion of female foetuses, it banned sex determination of the foetus (1); required the registration of all facilities with sex determination capabilities; and penalised not only doctors for violating the law but also the pregnant woman's family members for pressuring her to learn the sex of the foetus (4). The PNDT was revised in 2003 to the Pre-

Authors: Gajanan Phutke (gajananphutke@gmail.com), Senior Resident, Family Medicine, Jan Swasthya Sahyog, Ganiyari village, Chattisgarh, INDIA, and Global Health Fellow, The HEAL Initiative, CA 94612, USA; Timothy Laux (corresponding author - laux.timothy@gmail.com), Hospitalist, The HEAL Initiative, CA 94612 and Jan Swasthya Sahyog, Ganiyari village, Chattisgarh, INDIA; Priyank Jain (drpriyankjain@gmail.com), Department of Medicine, Cambridge Health Alliance, Cambridge, MA 02139, USA; Yogesh Jain (yogeshjain.jssbilaspur@gmail.com), Co-Founder, Jan Swasthya Sahyog, Ganiyari Village, Chattisgarh, 495112 INDIA.

To cite; Phutke G, Laux TS, Jain P, Jain Y. Ultrasound in rural India: A failure of the best intentions. Indian J Med Ethics. 2019 Jan-Mar;4(1)NS: 39-45. DOI: 10.20529/JJME.2018.040.

Published online on May 18, 2018.

Manuscript Editor:Vijayaprasad Gopichandran

Peer Reviewers: Padma Bhate-Deosthali and one more reviewer.

() Indian Journal of Medical Ethics 2018
Conception and Pre-Natal Diagnostic Techniques Act (PCPNDT Act) (1). The PCPNDT does not ban any specific technology but rather the discriminatory use of those technologies including ultrasound.

Despite good publicising and serious penalties, the PCPNDT Act had little effect on sex at-birth ratios $(1,5)$. The recently released National Family Health Survey 2015-16 showed that the sex ratio at birth rose from 914 to 916 over the previous 11 years though there was great variability at the state level $(6,7)$. Moreover, the PCPDNT Act has created conditions that further disadvantage some marginalised populations. Some commentators have noted concerns about the law's potential to catch women in a trap where giving birth to a girl results in remonstration at the hands of their husbands and families, while attempting sex selection invites prosecution by the government $(1,5)$.

In this article, we will argue that current regulations have restricted access to a highly effective and appropriate technology (diagnostic ultrasonography) in Indian healthcare that especially disadvantages poor and rural patients, thus raising ethical and justice concerns. It is difficult to argue that one ethical imperative outweighs another, yet we believe revisions of some aspects of the PCPNDT Act can both improve access to diagnostic ultrasonography for medical care in rural India, and also slow the misuse of this technology for sexselection.

\section{How did we get here? Non-maleficence and justice meet pragmatism}

The legislators who modified the PNDT Act in 2003 believed that the act of sex selection (and subsequent acts) was morally wrong. The ethical foundation of the Act is rooted in the principles of non-maleficence and justice. Even though the pregnant woman herself is often not directly harmed at the time of a sex determination ultrasound, the law aimed to prevent harm to the unborn female foetus and societal ills that can emanate from skewed sex-ratios. Allowing sex selective practices predisposes us to a future where women can be at greater risk of various forms of injustice - like sex trafficking or gender violence - due to their decreased numbers in the general population. India's turn in this legislative direction mirrored that of other nations $(1,5,8)$ including neighbours with similar cultural drivers, like China where concerns about ultrasound abuse have also been voiced (9-11).

However, enforcement of the law required a different approach, guided less by ethics and more by pragmatism. While data is not available about the conversations within the government about how this law moved from paper to action, we can conjecture based upon how it is enforced. 


\begin{tabular}{|c|c|}
\hline \multicolumn{2}{|c|}{$\begin{array}{c}\text { Table } 1 . \\
\begin{array}{c}\text { Selected medical conditions that can be diagnosed and selected } \\
\text { procedures that can be performed with POCUS / diagnostic } \\
\text { ultrasonography }\end{array}\end{array}$} \\
\hline Medical condition & Notes \\
\hline Hydatid cysts (23) & $\begin{array}{l}\text { Portable ultrasonography has proven of great } \\
\text { benefit in diagnosis and monitoring treatment } \\
\text { of echinococcal disease. }\end{array}$ \\
\hline $\begin{array}{l}\text { Deep venous } \\
\text { thrombosis (24) }\end{array}$ & $\begin{array}{l}\text { Bedside POCUS at two selected locations in } \\
\text { each leg is nearly as good as longer, more } \\
\text { complicated tests in their ability to detect deep } \\
\text { venous thromboses. }\end{array}$ \\
\hline Heart function (25) & $\begin{array}{l}\text { During triage, POCUS of the heart was effective } \\
\text { at both confirming clinical impression but also } \\
\text { frequently altered clinical management rapidly } \\
\text { at the bedside regarding heart function or } \\
\text { dysfunction. }\end{array}$ \\
\hline Lung function (26) & $\begin{array}{l}\text { POCUS can be used to differentiate between } \\
\text { different emergent pulmonary conditions } \\
\text { including COPD exacerbations, pneumonia, } \\
\text { pulmonary embolism and pulmonary edema. }\end{array}$ \\
\hline \begin{tabular}{|l|} 
Elevated intracranial \\
pressure (27-29)
\end{tabular} & $\begin{array}{l}\text { Ocular ultrasonography to measure ocular } \\
\text { nerve sheath diameter can be used to detect } \\
\text { elevated intracranial pressures including in } \\
\text { pediatric cerebral malaria and those with } \\
\text { hypertensive urgency or emergency. } \\
\end{array}$ \\
\hline Lepros & $\begin{array}{l}\text { Ultrasonography can be used to monitor } \\
\text { response to treatment in some types of leprosy. }\end{array}$ \\
\hline $\begin{array}{l}\text { Trauma and critical } \\
\text { care }(31,32)\end{array}$ & $\begin{array}{l}\text { POCUS can be used as a rapid and accurate } \\
\text { technique to evaluate the critically ill including } \\
\text { conditions ranging from life threatening } \\
\text { trauma to shock. }\end{array}$ \\
\hline Cardiac Arrest $(33,34)$ & $\begin{array}{l}\text { Ultrasonography can be used to monitor } \\
\text { presence or absence of cardiac function } \\
\text { during cardiac arrest, to determine underlying } \\
\text { etiology and monitor response (or lack of } \\
\text { response) to cardiopulmonary resuscitation. }\end{array}$ \\
\hline Procedure & Notes \\
\hline $\begin{array}{l}\text { Placement of } \\
\text { intravascular access } \\
(35-38)\end{array}$ & $\begin{array}{l}\text { Ultrasound can be safely and effectively } \\
\text { used to cannulate both the arterial and } \\
\text { venous systems and is often safer with lower } \\
\text { complication rates that attempting to place } \\
\text { such intravascular devices blindly. }\end{array}$ \\
\hline $\begin{array}{l}\text { Lumbar puncture } \\
(39-42)\end{array}$ & $\begin{array}{l}\text { Ultrasound can be used to accurately find the } \\
\text { necessary landmarks to safely perform lumbar } \\
\text { puncture, especially in children. }\end{array}$ \\
\hline $\begin{array}{l}\text { Aspiration of fluid } \\
\text { from various body } \\
\text { compartments (43-46) }\end{array}$ & $\begin{array}{l}\text { Ultrasound can be used to visualise fluid } \\
\text { pockets in the lungs or abdomen and safely } \\
\text { drain them for diagnostic or therapeutic } \\
\text { reasons. Before inserting the needle, } \\
\text { ultrasound can also be used to check that there } \\
\text { are no major blood vessels near the planned } \\
\text { site of needle insertion. }\end{array}$ \\
\hline
\end{tabular}

The Medical Termination of Pregnancy Act, 1971, gives a woman the right to an abortion up to twenty weeks gestational age under a number of circumstances in India (12). Sex selective practices could not be curtailed in this way. Legal experts have long known the difficulty of obtaining convictions based upon a person's motivations. The easiest, most direct way to limit sex selective abortion is prohibition of prenatal sex determination. Throughout India (and, indeed, the world) in-utero sex determination is largely performed by ultrasonography since the 1990s. Thus, a pragmatic approach
Table 2.

Selected remote and low resource settings where POCUS / diagnostic ultrasonography has been safely and successfully used \begin{tabular}{|l|l|}
\hline Setting & Brief summary \\
\hline
\end{tabular}

Lugufu refugee camp, After a four-day training, healthcare providers Kigoma District, in this refugee camp made frequent use of \begin{tabular}{l|l} 
Tanzania (47) & ultrasound for diagnostic testing.
\end{tabular}

Trauma care after 2010 Access to ultrasound greatly benefitted the Haitian earthquake triage of trauma patients after the 2010 Haitian (48) $\quad$ earthquake.

Ghanaian community Ultrasound was widely used in two separate (49) $\quad$ primary care clinics in Ghana.

\begin{tabular}{|l|l|}
\hline \multicolumn{2}{|c|}{$\begin{array}{c}\text { Table } 3 . \\
\text { Successful training of non-medical specialists in use of POCUS / } \\
\text { diagnostic ultrasonography }\end{array}$} \\
\hline Non-medical specialists & Use of POCUS \\
\hline $\begin{array}{l}\text { Briefly trained health workers (50) } \\
\text { and medical students (51) }\end{array}$ & $\begin{array}{l}\text { Screening for rheumatic heart } \\
\text { disease }\end{array}$ \\
\hline Special forces medics (52) & Trauma \\
\hline $\begin{array}{l}\text { Internal Medicine residents } \\
\text { (doctors-in-training) (53) }\end{array}$ & $\begin{array}{l}\text { Cardiac echocardiography at } \\
\text { bedside }\end{array}$ \\
\hline Prehospital providers (54) & Long bone fractures \\
\hline Dutch medical helicopter crew (55) & Chest ultrasound (heart and lungs) \\
\hline
\end{tabular}

is to police the use of this technology. Regulation of the law allowed only a small subset of medical professionals to perform ultrasound examinations: radiologists (the only group of doctors allowed to perform ultrasounds based solely on their degree qualifications), and obstetricians completing a six-month ultrasonography training course at selected training sites (13). The sale of all ultrasound machines was restricted through designated vendors and only to these qualified parties (1). The PCPDNT Act applies fully to all private, government and civic run hospitals $(14,15)$.

From a regulatory perspective, this decision was an absolute coup. The six-month training course was so long that it would be difficult for many full-time employed obstetricians to complete. Consultant radiologists are employed in diagnostic centres and hospitals generally found in urban areas. Within the government healthcare system, the smallest city that would offer a radiologist position is a district hospital. This would mean that one would only find radiologists in larger towns or cities and essentially eliminate the need to carefully police large swathes of rural regions of the country.

One can hardly fault legislators for taking a practical approach in turning this law into reality. Unfortunately, the PCPNDT created a pressing ethical and justice issue - reduced access to an appropriate healthcare technology. Thus, those large swathes of rural India that most stood to benefit from other applications of diagnostic ultrasonography were deprived of it.

\section{Would ultrasound be beneficial in rural India?}

The entire ethical argument that there is a justice component to lack of access to ultrasound hinges on whether ultrasound is effective and beneficial in settings like rural India.

Diagnostic ultrasonography has the potential to benefit rural 
Indians in ways that may not have been fully appreciated in 2003. While ultrasound has long been an established medical imaging modality, since 2003 the medical community has made greater use of what is now termed "point of care ultrasonography" (POCUS). POCUS refers to a form of diagnostic ultrasonography that can be brought to the patient's side - whether in emergency, outpatient, inpatient, intensive care settings, even in the back of an ambulance and be used in real time to gather data and make meaningful clinical decisions.

POCUS has been shown to effectively diagnose and treat many medical conditions (Table 1) and has been used effectively in remote and low resource settings around the world (Table 2) (16). POCUS does require some expertise to appropriately use and interpret, but these skills are not the sole province of the medical consultant and can be effectively taught to a variety of other medical professionals including those with less education with brief trainings (Table 3). Multiple reviews have been published on POCUS use in remote and low resource settings (17-19) including disaster relief (20).

Ultrasonography is an older medical imaging technology but one that has retained its role in the medical armamentarium due to its low costs, portability, ability to function on battery power without electricity, lack of pain, rapidity of results and lack of radiation exposure. In rural India, where patients often have limited funds, electricity is intermittent and long-term patient follow up is extremely difficult, ultrasound is clearly the imaging test of choice in a variety of circumstances.

This point is further elucidated by how POCUS is even making forays into higher resource settings where higher cost, higher resource imaging tests like computerised tomography (CT) scan or magnetic resonance imaging (MRI) are widely available. Emergency medicine and critical care physicians in the United States can now complete diagnostic ultrasonography fellowships (21) or certifications (22), as POCUS is so appropriate to emergency and ICU settings. If point-ofcare / diagnostic ultrasonography is effective enough that settings with alternative diagnostic modalities are teaching certifying and adopting it, there need to be unassailably strong arguments why it is not appropriate for rural India where such alternatives do not exist.

\section{Justice concerns: Unfairly shared burdens}

We believe the above demonstrates the potential benefits of POCUS and its natural fit for medical care in the realities of rural India. While never extensively studied, it is our contention that the unintended side effects of the PCPNDT Act and its regulation most heavily burden rural areas. India's rural poor already suffer from multiple other substantial burdens including large barriers to accessing care (56) and (if and when care is accessed) a high risk of financial ruin (57).

In rural areas, many health centres have few (if any) physicians and they almost certainly will not have a consultant radiologist. Similarly, the time and expense that must be invested in the government mandated, six-month ultrasonography training course renders that option a non-starter for many rural obstetrician gynecologists. This means that many rural health clinics and hospitals cannot legally keep an ultrasound machine. It would be remarkable to find an ultrasound machine in our region of rural Chhattisgarh in a primary health centre $(\mathrm{PHC})$ and even many community health centres $(\mathrm{CHC})$. We suspect the same to be true in other regions of rural India. While some rural practitioners will make do with the physical exam or a locally available X-ray, many rural patients will be referred for an ultrasound, CT or MRI at a distant urban facility. Even under the best of circumstances where the patient can find, pay for and perform the test, specialised expertise is needed to interpret CT and MRI images and can lead to delays in diagnosis. Delays in diagnosis are particularly burdensome in rural settings as patient follow up is often difficult because of structural barriers such as transportation and migrant labor. The realities of regulating and enforcing the PCPNDT function almost as a "poverty tax" where the poorest are made to shoulder a disproportionately large proportion of the unintended consequences of the PCPNDT law. We have a clear ethical and justice issue on our hands when a rural Indian patient can be provided with actionable information about his or her condition with an ultrasound and be saved time, travel, money, radiation exposure (in the case of CT) and delay, yet such care is being denied by limiting access to a simple diagnostic tool.

\section{Possible solutions}

Several workable solutions exist and we would like to propose two: a modification of the existing six-month ultrasonography training course, and encouraging collaborative relationships between radiologists and rural health centres.

The current six-month training course for ultrasonography is logistically difficult for most individuals but the spirit of the idea seems correct. One can imagine a general certification available to medical professionals from primary care, general and emergency specialties such as Family Medicine, Paediatrics, Internal Medicine, Emergency Medicine, General Surgery and Anaesthesiology. Much of this coursework could even be done close to home via online modules (where the internet is available) especially since many modern, portable ultrasounds interface with various other types of hand-held technologies (smart phones (58), USB flash drives) to securely store and transmit images. While such professionals would not have a radiologist's skill set or breadth of knowledge, they certainly could make actionable clinical decisions. More advanced coursework could also be made available as one progressed through levels of certification. The Delhi High Court opened this possibility in a February 17, 2016 ruling whereby it could not adjudicate the difference between a "mere MBBS" and those individuals currently allowed to perform ultrasounds in a meaningful way. The Court further clarified how these laws were never intended to comment on who was qualified to perform ultrasound examinations nor guaranteed their ethical character $(59,60)$. While the Supreme Court has recently stayed 
this decision, we interpret para 8 of the Supreme Court's ruling to mean asking the central government for greater clarity for "carrying out the provisions of the Act" (61). While perhaps a drawback in the short term, this might be a long-term opportunity whereby the Supreme Court leverages the central government to introduce new or modify existing coursework for certifying medical graduates in the safe and effective performance of ultrasonography, including in rural settings. We must note that our proposed solution cannot prevent nefarious use of ultrasound for prenatal sex determination any more than current coursework certifying practitioners in ultrasound diagnostics.

As noted previously, rural health care centres often lack the radiology specialist or trained obstetricians needed to register their own ultrasound machine/s. With the increasing connectivity of rural India and the safe, private transferring of ultrasound images from even remote locations (62), the PCPNDT law could be modified to reward collaboration as a means to improving care in rural India. The first step in this process would be to allow radiologists to register additional machines at facilities where they are not physically present (ideally in areas with large unmet healthcare needs) if each radiologist can demonstrate ongoing, meaningful work with the rural clinic or hospital that now has an ultrasound machine. This radiologist can train local staff in the acquisition of whatever imaging types are most pertinent to their care setting and aid in image interpretation. Difficult cases can be shared in near real time via the proliferation of dissemination techniques available. The Tamil Nadu health system does something very similar whereby all primary health centres (PHC) are now connected to Chennai and its medical specialists and expertise. Over 250 Medical Officers at over 125 PHCs have been trained in basic obstetric ultrasound with the help of Mediscan (63). A similar telemedicine model has been successfully tested in Nicaragua (64). While not without its flaws, such a system has multiple built in layers of protection against abuses and multiple potential whistleblowers: the consultant radiologist, the local practitioner making use of the ultrasound machine and the saved images documenting what was imaged. Similarly, such rural health centres that are collaborating with ultrasonography specialists could legally purchase ultrasound machines through relaxation of the stringent laws dictating which person and facilities can purchase an ultrasound machine in India today.

It should be noted that we are certainly not the first to propose modifications to the PCPNDT Act. Cardiologists and anaesthesiologists have previously filed court petitions requesting exemptions to perform ultrasound specific to their field in areas exempted from the PCPDNT and have been granted the same $(65,66)$. Ophthalmologists have already been exempted from the law's statutes, probably because the probes used in ocular ultrasonography cannot be used for foetal sex determination (67). Radiologists in Pune have previously filed petitions against the draconian enforcement of the PCPDNT Act $(68,69)$. While we are sympathetic to these ideas and changes, we recommend larger, systemic changes to how the law is regulated as opposed to a more piecemeal, specialty by specialty approach. The former is more likely to be of benefit to rural Indian patients.

\section{Striking the balance}

The serious challenge before us is how best to increase the positive use of ultrasound for healthcare in rural India, without simultaneously making it easier to perform antenatal sex determination for sex selection. We cannot simply move the dial on access to ultrasound and call it better, without considering potential rise in illegal use.

A potential for improved regulation is the use of the "silent observer" modality previously endorsed as feasible by the Supreme Court (70) and reiterated in its recent decision (61). In 2010, the silent observer was deployed in Kolhapur District in Maharashtra $(14,71)$. These silent observers were external, 250 GB hard drives that cost INR.3,95,000. They intended to keep images of all ultrasounds to monitor sex determination and quality of antenatal maternal health (72). They were attached to all registered ultrasound machines in private, government and civic hospitals (73). The use of these silent observers raised cost and privacy issues (71) and made no difference in sex-atbirth ratios (74). They were ultimately not implemented long term or state-wide despite the brief duration for which they were employed. Of note, these silent observer devices were easy to detach and key pieces of clinical information were easy to not record (72). Their brief trial period makes it difficult to conclude about the efficacy of this policing method.

Remote storage and transfer of imaging data has progressed substantially in the past eight years. Today, nearly all ultrasound machines (including those that can be purchased in India) have the ability to store or transfer images on internal, tamper-proof hard drives and, further, can be connected to wireless internet. As such, many can even be accessed remotely. Going forward, these tamper-proof, wireless connected machines should be the only ones available for purchase in India. This can realise a greater transparency than has previously been possible even with plugged in external hard drives. The revisions to the PCPNDT Act which we propose above would also need to be coupled with clear rules regarding image storage. Every ultrasonography at every facility must have a mechanism whereby all images acquired with its use are stored for a designated period of time and must be available for review by regulators with ease. These images must not be editable or erasable by the person performing the ultrasound and this storage should not further burden the ultrasonographer or radiologist with additional red tape. While it is not possible to know with certainty from looking at images of an antenatal ultrasound if that ultrasound was being performed for sex selection, there are tell-tale features that are highly suggestive of such behaviour. Only certain probes can perform antenatal ultrasounds and, as such, only those images would need reviewing. Regulators could download randomly selected images of interest and monitor from afar. In lower resource settings, regulators could access the tamper-proof central 
drive where images are stored and review them in a similar manner. Those machines with consistent patterns of worrisome imaging findings (or those centres with consistent inability to play by the rules) could be placed under disciplinary action and, if ongoing worrisome patterns are observed, have their ultrasound privileges revoked. We have no illusions about how difficult curbing sex selection has been and will be. We also recognise these changes do nothing to address unregistered ultrasound machines. The above changes only allow for greater efficiency in monitoring registered ultrasound machines over larger geographic regions which will be necessary to allow for greater access in those same geographic regions.

The crux of improved regulation would lie with the immutability of image deletion or manipulation and a machine that looks no different externally from one without wireless and tamper proof drive monitoring. Policing for illegal use is better than restricting access and trusting that licensed practitioners will adhere to legal practice. This immutability attempts to keep to the original spirit of the PNDT and PCPNDT laws while allowing greater access to ultrasonography.

\section{Conclusion}

The PCPNDT Act was written to prevent a number of societally unacceptable harms including the sex selection of unborn foetuses. To date, it has yet to meaningfully deliver its stated non-maleficence aims (2) and, in that it has minimally changed skewed sex ratios, the original justice concerns of activists and legislators remain unaddressed. However, the pragmatism required to enforce this law has had profound effects on the ability of rural Indians to access a beneficial medical technology (POCUS / diagnostic ultrasonography) and may have even inadvertently placed a heavier burden on the poorest and worsened health inequity in India, creating serious ethical and justice concerns. It is time to re-examine and update the law such that diagnostic ultrasonography can be made widely available in rural India at all levels, including in the public sector at PHCs and CHCs.

Competing interests / funding support : All co-authors report no relevant disclosures at this time. This study was internally funded by Jan Swasthya Sahyog.

Jan Swasthya Sahyog as an institution reports no disclosures and is funded by multiple funders including TATA Trusts, Oxfam India, Government of Chhattisgarh, AIIMSONIANS OF AMERICA, Association for India's Development and Friends of JSS in US and UK.

\section{References}

1. Kalantry S. Sex Selection in the United States and India: A Contextualist Feminist Approach. UCLA Journal of International Law and Foreign Affairs. Fall 2013.

2. Mallapur C. More Male Foeticides than Female: Dovt. Data Indicate Vast Under-reporting. IndiaSpend.com 2016 Aug 30 [cited 2018 May 11]. Available from: http://www.indiaspend.com/cover-story/ more-male-foeticides-than-female-govt-data-indicate-vast-underreporting-94517

3. Jha P, Kumar R, Vasa P, Dhingra N, Thiruchelvam D, Moineddin R. Low female[corrected]-to-male [corrected] sex ratio of children born in
India: national survey of 1.1 million households. Lancet. 2006 Jan 21;367(9506):211-8.

4. Hirve SS. Abortion law, policy and services in India: a critical review. Reprod Health Matters. 2004 Nov;12(24 Suppl):114-21.

5. Kalantry S. Women's human rights and migration : sex-selective abortion laws in the United States and India. Philadelphia, Pennsylvania:University of Pennsylvania Press; 2017.xii, 254 pp.

6. Rao M. One step forward, two back - India's unevent progress in correcting gender imbalance. Scroll.in. 2017 Apr 17[cited 2018 May 11]. Available from: https://scroll.in/pulse/834701/one-step-forward-twoback-indias-uneven-progress-in-correcting-its-gender-imbalance.

7. International Institute for Population Sciences. National Family Health Survey, India, 2015-16 [cited 2018 May 11].; Available from: http://rchiips. org/nfhs/nfhs4.shtml.

8. Unnithan M, Dubuc S. Re-visioning evidence: Reflections on the recent controversy around gender selective abortion in the UK. Glob Public Health. 2017 Jun;13(6):742-53.

9. Huang Y, Tang W, Mu Y, Li X, Liu Z, Wang Y, Li M, Li Q, Dai L, Liang J, Zhu J.. The Sex Ratio at Birth for 5,338,853 Deliveries in China from 2012 to 2015: A Facility-Based Study. PLoS One. 2016;11(12):e0167575.

10. Plafker T. Sex selection in China sees 117 boys born for every 100 girls. BMJ. 2002 May 25;324(7348):1233.

11. Zhou C, Wang XL, Zhou XD, Hesketh T. Son preference and sex-selective abortion in China: informing policy options. Int J Public Health. 2012 Jun;57(3):459-65.

12. Government of India. The Medical Termination of Pregnancy Act, 1971 [cited 2018 May 11]. Available from: https://indiankanoon.org/ doc/634810/

13. Indian Radiological \& Imaging Association. Gazette Notification Six Months Training Course in Ultrasonography to MBBS doctors. Available from: https://www.iria.in/pndt.php.

14. Mascarenhas A. Silent Observer helps Maharashtra district fight female foeticide. Indian Express; 2010 Aug 3[cited 2018 May 11]; Available from: http://archive.indianexpress.com/news/silent-observer-helpsmaharashtra-district-fight-female-foeticide/655278/.

15. Maharashtra Judicial Academy. Training Module and Handbook for Judicial Officers on Sex Selection and PCPNDT Act. United Nations Population Fund - India; 2014 [cited 2018 Available from: http://india. unfpa.org/en/publications/training-module-and-handbook-judicialofficers-sex-selection-and-pcpndt-act?page $=0 \% 2 \mathrm{C} 0 \% 2 \mathrm{C} 2$

16. Sippel S, Muruganandan K, Levine A, Shah S. Review article: Use of ultrasound in the developing world. Int J Emerg Med.2011 Dec 7;4:72.

17. Gharahbaghian L, Anderson KL, Lobo V, Huang RW, Poffenberger CM, Nguyen PD. Point-of-Care Ultrasound in Austere Environments: A Complete Review of Its Utilization, Pitfalls, and Technique for Common Applications in Austere Settings. Emerg Med Clin North Am. 2017 May;35(2):409-41.

18. Nelson BP,Melnick ER, Li J.Portable ultrasound for remote environments, part II: current indications.J Emerg Med. 2011 Mar;40(3):313-21.

19. Nelson BP, Melnick ER, Li J.Portable ultrasound for remote environments, Part I: Feasibility of field deployment.J Emerg Med.2011 Feb;40(2):190-7.

20. Wydo SM, Seamon MJ, Melanson SW, Thomas P, Bahner DP, Stawicki SP. Portable ultrasound in disaster triage: a focused review. Eur J Trauma Emerg Surg. 2016 Apr;42(2):151-9.

21. Emergency Ultrasound Fellowships. Available from: http:// eusfellowships.com/.

22. Chest: American College of Chest Physicians. Certificate of Completion Program: Critical Care Ultrasonography. Available from: http://www. chestnet.org/Education/Advanced-Clinical-Training/Certificate-ofCompletion-Program/Critical-Care-Ultrasonography.

23. Macpherson CN, Bartholomot B, Frider B. Application of ultrasound in diagnosis, treatment, epidemiology, public health and control of Echinococcus granulosus and E. multilocularis. Parasitology. 2003;127 Suppl:S21-35.

24. Lewiss RE, Kaban NL, Saul T. Point-of-Care Ultrasound for a Deep Venous Thrombosis. Glob Heart. 2013 Dec;8(4):329-33.

25. Kobal SL, Liel-Cohen N, Shimony S, Neuman Y, Konstantino Y, Dray EM, Horowitz I, Siegel RJ. Impact of Point-of-Care Ultrasound Examination on Triage of Patients With Suspected Cardiac Disease. Am J Cardiol.2016 Nov 15;118(10):1583-7.

26. Lichtenstein DA, Meziere GA. Relevance of lung ultrasound in the 
diagnosis of acute respiratory failure: the BLUE protocol. Chest. 2008 Jul;134(1):117-25.

27. Beare NA, Glover SJ, Lewallen S, Taylor TE, Harding SP, Molyneux ME. Prevalence of raised intracranial pressure in cerebral malaria detected by optic nerve sheath ultrasound. Am JTrop Med Hyg. 2012 Dec;87(6):985-8.

28. Robba C, Cardim D, Tajsic T, Pietersen J, Bulman M, Donnelly J, Lavinio A, Gupta A, Menon DK, Hutchinson PJA, Czosnyka M. Ultrasound noninvasive measurement of intracranial pressure in neurointensive care: $A$ prospective observational study. PLoS Med. 2017 Jul;14(7):e1002356.

29. Roque PJ, Wu TS, Barth L, Drachman D, Khor KN, Lovecchio F, Stapczynski S. Optic nerve ultrasound for the detection of elevated intracranial pressure in the hypertensive patient. Am J Emerg Med. 2012 Oct;30(8):1357-63.

30. Polat Ekinci A, Karabacak E, Tekin L, Ozarmagan G, Ozcakar L. Ultrasound imaging for the follow-up of patients with leprosy: a pictorial essay. $\mathrm{Br} J$ Dermatol. 2015 Jan;172(1):265-7.

31. Oren-Grinberg A, Talmor D, Brown SM. Focused critical care echocardiography. Crit Care Med. 2013 Nov;41(11):2618-26.

32. Schmidt GA, Koenig S, Mayo PH. Shock: ultrasound to guide diagnosis and therapy. Chest. 2012 Oct;142(4):1042-8.

33. Atkinson $P$, Bowra J, Milne J, Lewis $D$, Lambert $M$, Jarman $B$; Members of the International Federation of Emergency Medicine Sonography in Hypotension and Cardiac Arrest working group. International Federation for Emergency Medicine Consensus Statement: Sonography in hypotension and cardiac arrest (SHoC): An international consensus on the use of point of care ultrasound for undifferentiated hypotension and during cardiac arrest - CORRIGENDUM. CJEM. 2017 Jul;19(4):327.

34. Gaspari R, Weekes A, Adhikari S, Noble VE, Nomura JT, Theodoro D, et al. Emergency department point-of-care ultrasound in out-of-hospital and in-ED cardiac arrest. Resuscitation. 2016 Dec;109:33-9.

35. Agarwal A, Singh DK, Singh AP. Ultrasonography: a novel approach to central venous cannulation. Indian J Crit Care Med. 2009 Oct;13(4):213-6.

36. Conway DH, Wadsworth R. Portable ultrasound for central venous cannulation. Br J Anaesth. 1999 Dec;83(6):964.

37. Hatfield A, Bodenham A. Portable ultrasound for difficult central venous access. Br J Anaesth.. 1999 Jun;82(6):822-6.

38. Shiloh AL, Savel RH, Paulin LM, Eisen LA. Ultrasound-guided catheterization of the radial artery: a systematic review and metaanalysis of randomized controlled trials. Chest. 2011 Mar;139(3):524-9.

39. Abo A, Chen L, Johnston P, Santucci K. Positioning for lumbar puncture in children evaluated by bedside ultrasound. Pediatrics. 2010 May;125(5):e1149-53.

40. Kim S, Adler DK. Ultrasound-assisted lumbar puncture in pediatric emergency medicine. J. Emerg Med. 2014 Jul;47(1):59-64.

41. Peterson MA, Pisupati D, Heyming TW, Abele JA, Lewis RJ. Ultrasound for routine lumbar puncture. Acad Emerg Med. 2014 Feb;21 (2):130-6.

42. Williams $S$, Khalil M, Weerasinghe A, Sharma A, Davey R. How to do it: bedside ultrasound to assist lumbar puncture. Pract Neurol. 2017 Jan;17(1):47-50.

43. Feller-Kopman D. Ultrasound-guided thoracentesis. Chest. 2006 Jun;129(6):1709-14.

44. Mercaldi CJ,Lanes SF.Ultrasound guidance decreases complications and improves the cost of care among patients undergoing thoracentesis and paracentesis. Chest. 2013 Feb 01;143(2):532-8.

45. Nazeer SR, Dewbre H, Miller AH. Ultrasound-assisted paracentesis performed by emergency physicians vs the traditional technique: a prospective, randomized study. Am J Emerg Med. 2005 May;23(3):363-7.

46. Stone JC, Moak JH. Feasibility of sonographic localization of the inferior epigastric artery before ultrasound-guided paracentesis. Am J Emerg Med. 2015 Dec;33(12):1795-8.

47. Adler D, Mgalula K, Price D, Taylor O. Introduction of a portable ultrasound unit into the health services of the Lugufu refugee camp, Kigoma District, Tanzania. Int J Emerg Med. 2008 Dec;1 (4):261-6.

48. Shah S, Dalal A, Smith RM, Joseph G, Rogers S, Dyer GS. Impact of portable ultrasound in trauma care after the Haitian earthquake of 2010. Am J Emerg Med. 2010 Oct;28(8):970-1.

49. Spencer JK, Adler RS. Utility of portable ultrasound in a community in Ghana.J Ultrasound Med. 2008 Dec;27(12):1735-43.

50. Engelman D, Kado JH, Remenyi B, Colquhoun SM, Carapetis JR, Donath S, Wilson NJ, Steer AC. Focused cardiac ultrasound screening for rheumatic heart disease by briefly trained health workers: a study of diagnostic accuracy. Lancet Glob Health. 2016 Jun;4(6):e386-94.

51. Shmueli H, Burstein Y, Sagy I, Perry ZH, Ilia R, Henkin Y, Shafat T, LielCohen N, Kobal SL. Briefly trained medical students can effectively identify rheumatic mitral valve injury using a hand-carried ultrasound. Echocardiography. 2013 Jul;30(6):621-6.

52. Crisp JD. Portable ultrasound empowers Special Forces medics. J Spec Oper Med. 2010 Winter;10(1):59-62.

53. Alexander JH, Peterson ED, Chen AY, Harding TM, Adams DB, Kisslo JA, Jr. Feasibility of point-of-care echocardiography by internal medicine house staff. Am Heart J. 2004 Mar;147(3):476-81.

54. Heiner JD, McArthur TJ. The ultrasound identification of simulated long bone fractures by prehospital providers. Wilderness Environ Med. 2010 Jun;21(2):137-40.

55. Ketelaars R, Hoogerwerf N, Scheffer GJ. Prehospital chest ultrasound by a dutch helicopter emergency medical service. J Emerg Med. 2013 Apr;44(4):811-7.

56. Katyal A, Singh PV, Bergkvist S, Samarth A, Rao M. Private sector participation in delivering tertiary health care: a dichotomy of access and affordability across two Indian states. Health Policy Plan. 2015 Mar;30 Suppl 1:i23-31.

57. Rao M, Ramachandra SS, Bandyopadhyay S, Chandran A, Shidhaye R, Tamisettynarayana S, Thippaiah A, Sitamma M, Sunil George M, Singh V, Sivasankaran S, Bangdiwala SI.Addressing healthcare needs of people living below the poverty line: a rapid assessment of the Andhra Pradesh Health Insurance Scheme. Natl Med J India. 2011 Nov-Dec;24(6):335-41.

58. Becker DM, Tafoya CA, Becker SL, Kruger GH, Tafoya MJ, Becker TK. The use of portable ultrasound devices in low- and middle-income countries: a systematic review of the literature. Trop Med Int Health. 2016 Mar;21(3):294-311.

59. High Court of Delhi at New Delhi. Indian Radiological And Imaging Association (IRIA) vs Union of India and Anr and Indian Medical Association vs Union of India And Sonological Society of India vs Union of India \& Anr. 2016 Feb 17 [cited 2018 May 11]. Available from: http://lobis.nic.in/ddir/dhc/RSE/judgement/17-02-2016/ RSE17022016CW69682011.pdf.

60. Meghna. Delhi High Court Judgement clarifies who can do an ultrasound. 2016 Feb 14 [cited 2018 May 11]. Available from: https:// medicaldialogues.in/delhi-high-court-judgement-clarifies-who-cando-an-ultrasound/.

61. Ashok KM. Mandatory Training for Ultrasonography: SC Stays Delhi HC Judgment in Indian Radiological And Imaging Association Case [Read Order]. LiveLaw.in. 2018 Mar 15[cited May 11, 2018]. Available from: http://www.livelaw.in/mandatory-training-ultrasonography-sc-staysdelhi-hc-judgment-indian-radiological-imaging-association-case-readorder/.

62. Ogedegbe C, Morchel H, Hazelwood V, Hassler C, Feldman J. Demonstration of novel, secure, real-time, portable ultrasound transmission from an austere international location. Conference proceedings: Annual International Conference of the IEEE Engineering in Medicine and Biology Society IEEE Engineering in Medicine and Biology Society Annual Conference. August 2012;2012:5794-7.

63. MediScan. Training of Medical Officers in Basic Obstetric Ultrasound Overview. Available from: http://www.mediscansystems.org/training/ nrhm_overview.asp.

64. Kolbe N, Killu K, Coba V, Neri L, Garcia KM, McCulloch M, Spreafico A, Dulchavsky S. Point of care ultrasound (POCUS) telemedicine project in rural Nicaragua and its impact on patient management. $J$ Ultrasound. 2014 Sep 20;18(2):179-85.

65. Shrivastav S. Doctors demand exclusion of echocardiography from PCPNDT Act. Times of India [updated 2013 Aug 11; cited 2018 May 11]. Available from:https://timesofindia.indiatimes.com/city/nagpur/ Doctors-demand-exclusion-of-echocardiography-from-PCPNDT-Act/ articleshow/21751688.cms .

66. Dr. Rajendra G. Goyal \& Others vs. State of Maharashtra \& Others (Writ Petition Lodging No. 2059 of 2012). High Court of Judicature at Bombay; 2012.

67. Vaidya V. Major respite to Ophthalmologists, exempted from PCPNDT Act. Vaidyavikas.blogspot.in. 2015 Nov 12 [cited 2018 May 11]. Available from: http://vaidyavikas.blogspot.in/2015/11/major-respite-toophthalmologists.html 
68. Isalkar U. Pune: Radiologists demand amendment to PCPNDT Act Healthworld (From the Economic Times). 2015 Dec 9 [cited 2018 May 11]. Available from: https://health.economictimes.indiatimes.com/ news/industry/pune-radiologists-demand-amendment-to-pcpndtact/50109294.

69. Mascarenhas A. IMA to move SC against PCPNDT Act provisions Indian Express. 2014 Apr 8[cited 2018 May 11]. Available from: http:// indianexpress.com/article/india/india-others/ima-to-move-sc-againstpcpndt-act-provisions-2/.

70. Indian Radiological and Imaging Association vs. Union of India (W.P. (C) 6968/2011). High Court of Delhi at New Delhi; 2016.

71. Masand P.'Silent Observer' sonography model for state? Times of India. 2011 Jan 30 [cited 2018 May 11]. Available from: https://timesofindia. indiatimes.com/city/mumbai/Silent-observer-sonography-model-for- state/articleshow/7387461.cms.

72. Kore SS. Understand the Silent Observer Device SIOB. Waranahealth com. 2011 Dec 14 [cited 2018 May 11]. Available from: http://www. waranahealth.com/understand-the-silent-observer-device-siob.aspx.

73. Purandare V. Tracking devices on songraphy machines. Asian Age; 2017 Aug 22 [cited 2018 May 11]. Available from: http://www.asianage.com/ metros/mumbai/220817/tracking-devices-on-sonography-machines. html.

74. Srivastava K. Exclusive: Maharashtra government's Silent Observer can do little to save girl child. DNA India. Updated 2011 Sep 19 [cited 2018 May 11]. Available from: http://www.dnaindia.com/mumbai/reportexclusive-maharashtra-government-s-silent-observer-can-do-little-tosave-girl-child-1588899.

\section{Cooperation in confidential withholding of HIV status from partners of sexually-active patients: A role for organisational moral agency}

\section{PETER A DEPERGOLA II}

\section{Abstract}

An increasingly blurred understanding of the conditions under which clinicians may withhold HIV seropositive status from partners of patients who are sexually active and who do not intend to disclose suggests a critical need to revisit the relationship between the principle of confidentiality, the moral and legal duties to warn at-risk third parties, and the organisational ethics surrounding licit cooperation with wrongdoing in the effort to uphold professional moral responsibility. This essay grounds its argument in two, straightforward premises: (i) the ethical principle of cooperation is an indispensable measure of the moral licitness of instances of complicity with wrongdoing; (ii) some instances of material organisational complicity vis-à-vis confidential withholdings of HIV seropositive status from partners of sexually active patients both meet and successfully employ the standards of the ethical principle of cooperation. Drawing from this syllogism, the essay argues that, in Type II cases, healthcare organisations may (initially and on certain conditions) materially cooperate in withholding the HIV seropositive status of patients from partners with whom patients are sexually active, and to whom patients do not intend to disclose HIV seropositive status, in the effort to honour professional obligations of privacy, confidentiality, and fidelity in a manner that is both legally licit and morally justifiable.

\footnotetext{
Author: Peter A DePergola II (drpeterdepergola@gmail.com), Assistant Professor of Medicine, University of Massachusetts Medical School, Worcester, MA, USA; Assistant Professor of Medicial Humanities, College of Our Lady of the Elms, Chicopee, MA, USA.

To cite: DePergola PA II. Cooperation in confidential withholding of HIV status from partners of sexually-active patients: A role for organisational moral agency. Indian J Med Ethics. 2019 Jan-Mar;4(1)NS: 45-9. DOI:10.20529/ IJME.2018.080.

Published online on October 29, 2018

OIndian Journal of Medical Ethics 2018
}

\section{Introduction}

For the past two decades, guidelines of the United States Public Health Service (1) have recommended that individuals infected with human immunodeficiency virus (HIV) notify their sexual partners (2) ${ }^{1}$. Failure to disclose HIV seropositive status has been condemned as a moral and legal offence subject to both civil liability and criminal prosecution (3). In order to shield individuals living with HIV from disadvantages that may inhibit them from undergoing testing or from transparent disclosure of HIV status, their rights to privacy must be protected. This necessity underscores and invigorates the argument that clinicians, who have a (prima facie) moral obligation respect patients' confidentiality, should be strictly bound not to disclose the HIV seropositive status of patients without their consent or without other legal justification. However, competing with the need to safeguard the privacy of individuals living with HIV is the public health necessity of curbing the spread HIV (1). The drive to halt the spread of the pandemic, some argue, requires the adoption of measures such as informing the sexual partners of individuals whose HIV seropositive status has been ascertained through testing (4). Hence, such notification would enable uninfected partners to protect themselves against HIV infection, either by avoiding unprotected sex with infected partners or by abstaining from sexual intercourse with them. For some classes of medical professionals, striking a balance between these competing private and public health interests can breed serious ethical dilemmas on both professional and organisational levels (5).

An increasingly blurred understanding of the conditions under which clinicians may legitimately withhold HIV seropositive status from partners of patients who are sexually active and who do not intend to disclose suggests a critical need to revisit the relationship between the notion of confidentiality, the moral and legal duties to warn atrisk third parties, and the organisational ethics surrounding licit cooperation with wrongdoing in the effort to uphold 